\title{
Editorial: o editor em nova casa
}

\section{Prezados leitores}

Assim como no ano de 2019, o editor não teve fôlego suficiente para redigir um editorial num tom mais ensaístico como é prática na maior parte das edições da RECADM. Como a edição é finalizada no mês de agosto para estar no ar no início de setembro, a retomada das aulas imediatamente após o período de férias vem minando recorrentemente o foco e a energia do editor em desenvolver atividades além das urgentes e emergenciais. Espero, na primeira edição de 2021, redigir um belo editorial para compensar a ausência nesta edição.

Também para o ano de 2021, estamos refletindo sobre a possibilidade de a RECADM aumentar o número de publicações, passando de 18 artigos anuais para 21, já que o número de submissões de qualidade vem crescendo. Isso implica em um pouco mais de trabalho e aumento de custos, mas é algo que deve ser seriamente considerado para não comprometer o fluxo de publicações do periódico.

Apesar das questões que nos espera no futuro, gostaria de anunciar que o editor do periódico está de casa nova, assumindo como Professor Visitante na Universidade Federal de Uberlândia a partir do dia 1 de setembro, coincidentemente, o dia em que esta edição entra no ar. Fica minha imensa gratidão ao Programa de Pós-Graduação em Administração da UniGranRio, que me acolheu deste o dia primeiro de fevereiro de 2013, possibilitando que eu pudesse conduzir meu trabalho como professor e pesquisador. Ao Programa de Pós-Graduação em Administração da Universidade Federal de Uberlândia, agradeço antecipadamente a confiança em meu trabalho, dando-me espaço para poder contribuir com o corpo docente e discente.

Apesar da mudança de casa do editor, a RECADM permanece na mesma casa, pois é editada pelo Instituto Brasileiro de Estudos Sociais (IBEPES), que não só fomenta financeiramente o periódico, mas também dá todas as condições para que ele ganhe cada vez mais espaço na comunidade acadêmica da área de administração. Com isso, mantêm-se a continuidade dos trabalhos, não comprometendo em nada a qualidade do processo editorial.

\section{Nesta Edição}

Nossa última edição do ano de 2020, que infelizmente está sendo publicada durante a pandemia ocasionada pelo coronavírus, traz artigos extremamente interessantes e relevantes. Apesar da diversidade de temas, todos os artigos têm uma característica que tentamos incorporar como essencial no periódico, que é a preocupação com a contribuição teórica, seja por meio de novas ideias, ou a partir de investigações empíricas ou de revisões sistemáticas. É uma tarefa relativamente difícil garantir tais
Luciano Rossoni (iD,

Editor da RECADM

Universidade Federal de Uberlândia, Brasil

Irossoni@gmail.com 
contribuições, pois além de ser uma revista generalista, infelizmente, ao meu ver, a área de administração ainda tem dificuldade em aceitar, ou talvez compreender, a importância da teoria para a construção e consolidação do conhecimento científico e acadêmico. Isso se dá em parte porque muitos vêm incorporando que a ideia de "impacto" remete aos usos externos da ciência, o que têm seu mérito. Todavia, a RECADM escolheu como sua audiência os pesquisadores e a academia, pois o conhecimento como atividade humana vai além de sua utilidade imediata, cuja reflexividade não pode ser reduzida ao campo da aplicação, mais ainda à aplicação gerencial, cujos interesses servem muito mais a uma concepção de controle autocrático do que a uma lógica racional de organização.

Os artigos desta edição demonstram nossa preocupação com a atividade de "conhecer", uma vez que, no primeiro artigo desta edição, Patricia Ayumi Hodge e Alessandra de Sá Mello da Costa empreendem uma discussão bastante pertinente acerca do papel dos estudos sobre a memória e sobre a história oral na pesquisa organizacional. $\mathrm{O}$ artigo intitulado "Do particular para o geral: memória, história oral e estudos organizacionais", as autoras apontam que os estudos de memória organizacional vêm sendo criticados por sua visão instrumental, a-histórica. Por essa razão, elas propõem que a História Oral é mais uma possibilidade teórico-metodológica aos estudos de memória nas organizações, por meio da discussão (1) sobre as distintas historiografias dos estudos de memória e da História Oral, assim como seus respectivos entrelaces com a pesquisa organizacional, e (2) sobre dois possíveis caminhos para se partir da memória individual para a social, apresentando exemplos clássicos da literatura de História Oral.

Já no segundo artigo, "Corrupção organizacional e uma justificação decolonial para as práticas de whistleblowing", Felipe Fróes Couto, José Vitor Palhares e Alexandre de Pádua Carrieri exploram as noções de corrupção organizacional e sua respectiva denúncia (whistleblowing), a partir do olhar decolonial trazido pelo filósofo Enrique Dussel. Para tanto, os autores apresentam a visão das organizações como instâncias de mediação, que possuem existência delegada e que devem cumprir certos requisitos para serem legitimadas. Em seguida, exploramos como a corrupção organizacional deriva de um exercício fetichizado do poder. Ademais, notamos que o ato de whistleblowing pode ser visto como um impulso de alteridade em que o sujeito, ainda que a custo de sua própria vida e bem-estar, é guiado pela responsabilidade com o outro. Práticas de whistleblowing, quando analisadas à luz do pensamento de Dussel, podem ser justificadas como o desejo de superação das injustiças individuais por um dever ético de servir ao coletivo.

O terceiro artigo desta edição, de autoria de Solon Bevilacqua, cujo título é "Aspectos determinantes no consumo masstige", investigou o consumo masstige sob a lente do egoísmo ético, intimamente relacionado ao prazer e associado aos construtos diferenciação, exclusividade, funcional (atributos), status e tradição. Buscando fundamentar seus argumentos em autores evolucionistas, cuja discussão centrou-se em torno da natureza e 
cultura, o autor reinterpreta uma das dimensões do consumo: prazer como egoísmo ético. Os achados da pesquisa indicam que a dimensão prazer egoísmo ético para o consumo masstige é estruturada pela tradição, status e características funcionais do produto, ressaltando implicações para os estudos do consumo.

No quarto artigo, "Comportamento do consumidor em relação a produtos sustentáveis: uma revisão sistemática de literatura", os autores Luciana Faluba Damázio, Leonardo Antunes Nogueira Coutinho e Helena Belintani Shigaki realizam uma revisão sistemática de literatura sobre o comportamento do consumidor em relação aos produtos sustentáveis, a fim de identificar os fatores que interferem no comportamento, bem como definir os atributos e a percepção do consumidor frente ao tema sustentabilidade. Nesse estudo, os autores identificaram onze fatores de influência nas práticas de sustentabilidade no comportamento do consumidor de produtos sustentáveis - ambiente, idade, nível educacional, classe econômica, gênero, consciência, preocupação com a própria imagem, emoção, acesso à informação, confiança e hábito - e sete em relação aos atributos e percepção do consumidor acerca de sustentabilidade - eco-friendly, garantia de origem, saúde do consumidor, fair trade, teste em animais, recicláveis e ingredientes naturais.

O quinto artigo, de autoria de Carla Cristina Silva e Lucilaine Pascuci, "Processo estratégico emarranjos produtivos locais: o desafio da cooperação", analisa como ocorre o processo estratégico em um Arranjo Produtivo Local (APL) de desenvolvimento de softwares. Para tanto, examinou-se a influência de aspectos racionais e não racionais como sensemaking, criatividade, feeling e experiência nas estratégias adotadas pelos principais atores do APL. Os resultados apontam que o processo estratégico do APL assume um caráter técnico e artesanal, cuja dinâmica permitiu a identificação de um padrão no processo de formação de estratégias em APL que, apesar da pluralidade de atores, demonstrou o esforço na promoção de alinhamento entre decisões conjuntas e ações individuais.

Por fim, no sexto e último artigo desta edição, Hélida Norato e Anderson Ribeiro Duarte, no artigo intitulado "Associações entre características de organizações híbridas e elementos contextuais de resiliência organizacional”, identificam características singulares de organizações híbridas, apresentando um mapa conceitual desenvolvido por meio de uma estratégia concept-centric para sistematizar novas relações entre dimensões e características singulares, além de propor um modelo processual. Os autores verificaram que as características singulares utilizadas no mapa conceitual reforçam processos capazes de contribuir para resiliência organizacional, destacando-se três características de organizações híbridas: (i) missão, benefícios e impactos pretendidos; (ii) impacto social; (iii) governança e parcerias. Ademais, valores fundamentais como integração, interdependência e cooperação ficaram evidentes dentre as dimensões sob investigação. 
Gostaria de ressaltar que ainda está no ar a nossa primeira chamada especial "Verso, Prosa, Drama e Ficção: Literatura e Organizações" conduzida pelos editores convidados Ana Sílvia Rocha Ipiranga e Luiz Alex Silva Saraiva. O prazo de submissão se encerra no dia 30 de novembro de 2020 e estamos ansiosos por receber artigos sobre a temática.

Despeço-me, novamente, desejando saúde para todos os membros da comunidade da RECADM, na torcida de que nada de essencial falte nesse momento de privação. Lembrando que, ao escrever o editorial anterior, tinha em mente que os impactos da Covid-19 seriam transitórios, em que o pior já tivesse passado. Estava completamente enganado, pois o número diário de mortes não cessa, as demissões continuam e a esperança de retorno à normalidade está cada vez mais distante. Infelizmente, ainda estamos acometidos de problemas sérios de gestão da crise, o que dificulta ser otimista, pelo menos em curto prazo.

No entanto, apesar dos pesares, os avaliadores continuam incansáveis (os autores mais ainda, pois não param de submeter artigos), sem contar na maravilhosa equipe de suporte da RECADM, que facilita a vida deste editor. Apesar de editor "chefe", atuo quase de forma solo no que se refere à gestão do periódico. Ainda bem que posso contar com o apoio financeiro do Instituto Brasileiro de Estudos e Pesquisas Sociais (IBEPES), que ainda está superando essa crise econômica, pois, sem tal apoio, esse periódico padeceria. E que no próximo editorial, se não tivermos já em meio da aplicação de vacinas, que pelo menos a doença esteja controlada.

Uma prazerosa leitura,

\section{Luciano Rossoni}

Editor da RECADM 